\section{Professional educators wanted}

Waterpik is looking for practising dental hygienists or dental therapists to become independent Professional Educators in Scotland.

If you are a confident oral health educator that can arrange and deliver Lunch and Learn presentations on the advantages of water flossing and the benefits of the Waterpik oral health product range, apply now.

You will need at least three years' clinical experience, good computer skills, a valid driving licence and a car.

For more details or to apply, send your CV to: Charlotte.Gowers@churchdwight.com. For more information on Waterpik products visit www.waterpik. co.uk. Waterpik products are available from Amazon, Asda, Costco UK, Boots and Superdrug online and in stores across the UK and Ireland.

\section{Avoid metal-mouth, choose ceramic}

More and more patients are seeking aesthetic orthodontic options. Avoid metal-mouth and choose ceramic with Clarity ADVANCED ceramic brackets from 3M Oral Care.

Clarity ADVANCED ceramic brackets from $3 \mathrm{M}$ have been purposefully designed to blend with a wide variety of tooth shades, helping to ensure an aesthetic appearance.

Patient comfort is also enhanced during treatment as Clarity ADVANCED ceramic brackets have a unique dome shaped design and rounded edges to minimise binding and notching.

So if you want an aesthetic, comfortable option for your patients, choose Clarity ADVANCED ceramic brackets.

Find out more by contacting the team at 3M Oral Care today. For more information, call 08458734066 or visit http:// solutions.3m.co.uk/wps/portal/3M/ en_GB/orthodontics_EU/Unitek/.

\title{
Deprivation index added to patient software
}

Dentally's latest product update benefits its NHS Scotland customers, as it has introduced the Scottish Index of Multiple Deprivation (SIMD) identification within Dentally.

The Scottish Index of Multiple

Deprivation is an identification of deprived areas in Scotland compiled by a number of different indicators which include income, employment, health, education, geographical access, crime and housing.

Following feedback from customers, SIMD has been incorporated into Dentally so that it will appear on a patient's record. If you need to look up the patient's SIMD quotient, you can simply click on the magnifying glass and the score will be shown. By using the patient's post code, it will notify the dental practitioner whether or not the patient lives within one of the

\section{Superhero bash planned for charity}

Bridge2Aid's SuperBash is back at the BDIA Dental Showcase this year and is set to be bigger and better than ever before.

Taking place on Friday 18 October and embracing the theme of superheroes, putting the fun back in fundraising is sure to follow, as we find out who will win on the wipe-out or complete the assault course in the fastest time.

This year, a desire to dance is guaranteed as Tommy and The Fuse take to the stage deprived areas listed in the index. Once you have clicked to the magnifying glass to show the score, it will retain this data on the patient's record for future reference.

This new feature will help dentists to identify patients that may require different levels of care and also assist dental practices in managing their claims more effectively, as NHS Scotland will increase the claim payment for treatment of a patient who lives in one of the deprived areas.

If you would like to find out more about these exciting new product developments or arrange demo and join the 5,000 dental professionals who work smarter, work remotely and work securely with Dentally, simply visit Dentally's website or email hello@dentally.co. For more information visit: https://dentally. co/ or call 02038565610 .

\section{All you need to know about bone management}

Do you want to learn how to effectively manage bone levels during implant treatment? myplant, a sister company of the world-famous Meisinger brand, is here to help, with a series of bone management courses led by industry leading professionals that will take place throughout 2020.

These exclusive courses will guide clinicians through the ins and outs of effective bone management, helping them to focus their skills, explore new methods and cover all clinical areas.

Places on these courses will be limited, so make sure you keep a lookout for dates with a set list so extensive everyone will be happy.

What's more, the food will be as delicious as ever, with a two-course buffet catering for meat eaters, pescatarians, vegetarians and vegans alike. As for dessert, there are seven, each tailored to a superhero or baddy's personality. (Menu details are available at https://bridge2aid. org/bridg2aids-superbash/).

Can't bear to miss out on all the fun and delicious food? Then simply click on the link to purchase your tickets today: https:// bridge2aid.charitycheckout.co.uk/superbash.

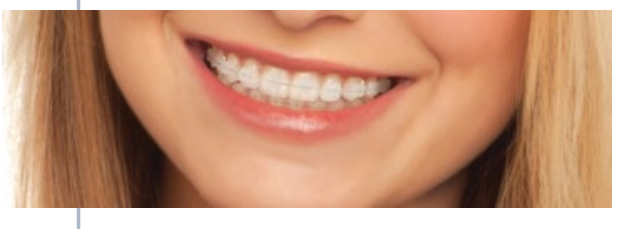

so that you don't miss out. You can find out more about myplant's bone management educational programme by contacting the team today.

To find out more, visit www.myplant-dental.com, email order@myplant-dental.com or call 004921311259465.

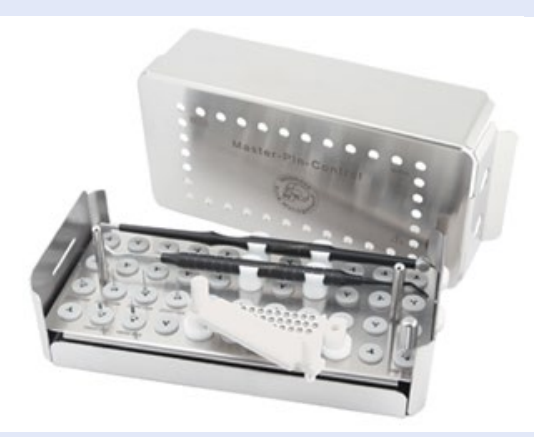

